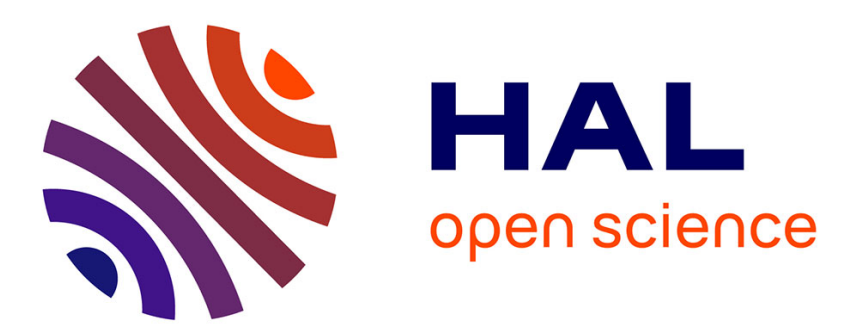

\title{
Agglomeration of durum wheat semolina: Thermodynamic approaches for hydration properties measurements
}

Driss Oulahna, Anne Hebrard, Bernard Cuq, Joel Abecassis, Jacques Fages

\section{- To cite this version:}

Driss Oulahna, Anne Hebrard, Bernard Cuq, Joel Abecassis, Jacques Fages. Agglomeration of durum wheat semolina: Thermodynamic approaches for hydration properties measurements. Journal of Food Engineering, 2012, 109 (3), pp.619-626. 10.1016/j.jfoodeng.2011.10.003 . hal-01267768

\section{HAL Id: hal-01267768 \\ https://hal.science/hal-01267768}

Submitted on 10 Jan 2018

HAL is a multi-disciplinary open access archive for the deposit and dissemination of scientific research documents, whether they are published or not. The documents may come from teaching and research institutions in France or abroad, or from public or private research centers.
L'archive ouverte pluridisciplinaire HAL, est destinée au dépôt et à la diffusion de documents scientifiques de niveau recherche, publiés ou non, émanant des établissements d'enseignement et de recherche français ou étrangers, des laboratoires publics ou privés. 


\title{
Agglomeration of durum wheat semolina: Thermodynamic approaches for hydration properties measurements
}

\author{
Driss Oulahna ${ }^{\mathrm{a}}$, Anne Hebrard ${ }^{\mathrm{a}}$, Bernard Cuq ${ }^{\mathrm{b}}$, Joël Abecassis ${ }^{\mathrm{b}}$, Jacques Fages ${ }^{\mathrm{a}, *}$ \\ ${ }^{a}$ Université de Toulouse, Ecole des Mines Albi, RAPSODEE Centre, CNRS, 81013 Albi, France \\ b INRA-Montpellier SupAgro, UMR 1208 IATE, 34060 Montpellier, France
}

Keywords:

Diffusion

Durum wheat semolina

Hydration

Mixing calorimetry

Solid-water interactions

Thermodynamic properties

\begin{abstract}
A B S T R A C T
In the manufacturing process of pasta or couscous, durum wheat semolina agglomeration comprises suc cessive steps, in particular a wetting and hydration stage. In this step, interactions between water mol ecules and semolina grains contribute to the agglomeration properties. Hydration properties of semolina have been recognised to play an important role in agglomeration.

The hydration properties of semolina have been characterised using various methods which can be divided into 2 groups according to the water addition: liquid or vapour. Several parameters can be used to describe hydration properties and hydration mechanisms, such as: water sorption capacity, hydration kinetics, diffusion of water within the solid (swelling, dissolution, solid water affinity and thermody namic properties).

In this study, sorption isotherms and diffusion coefficients have been determined by gravimetric method in specific conditions. The immersion enthalpy of the semolina and its main sub components, starch and gluten have been measured by mixing micro calorimetry. Hydration thermodynamic proper ties, Gibbs free energy, enthalpy and entropy, were calculated from these experimental data. It was found that hydration by vapour or liquid water is an exothermic reaction.

The determined diffusion coefficient was used to estimate the stabilisation time of water within the solid. Being high at low relative humidity, the diffusion coefficient decreases during progressive satura tion of solid sites. Sorption energy and solid water affinity yield information about the type of interaction between water molecules and solid sites. The drop in the sorption energy during the increase in water content can be attributed to a decrease in solid water interactions. The hydration energy of durum wheat semolina in vapour or liquid water was found to be low. This corresponds to the energy input needed to generate contact between water and grain surface and for mixture homogenisation.
\end{abstract}

\section{Introduction}

Agglomeration process, widely used in cereal industry, usually requires a liquid binder addition. Generally, solid water interac tions can be broken down into two simultaneous or successive steps (Fig. 1). From durum wheat semolina, the manufacturing process of pasta or couscous consist of different stages among which a wetting and hydration step, necessary for grain agglomer ation under mixing conditions. During hydration, the solid water interactions as described in Fig. 1, takes into account two types of solid reactivity with water: surface and internal reactivity mech anisms. In this paper, we present the hydration properties of durum wheat semolina by water linked to internal reactivity (see Fig. 2).

\footnotetext{
* Corresponding author. Tel.: +33 563493 141; fax: +33 563493025

E-mail address: jacques.fages@mines-albi.fr (J. Fages).
}

Solid hydration properties can be assessed by liquid or vapour water addition. For liquid water addition, two methods are currently used: solid immersion in excess water or liquid distribu tion in a capillary system (Baumann, 1966). For vapour water addi tion, two methods can be used: gas chromatography (Buckton, 1992; Gutierrez and Rubio, 1999) or static gravimetry; the latter being considered as the reference method (Levoguer and Booth, 1997). Depending on the analytical method, hydration properties can be described by various parameters such as:

- Water uptake at a given relative humidity or in liquid phase.

- Stabilisation time for reaching the equilibrium between relative humidity and water content.

- Water adsorption mechanisms.

- Solid water affinity.

- Diffusion coefficient of water within the solid.

- Structural and physico chemical modifications due to hydration as a function of temperature. 


\begin{tabular}{|c|c|c|c|}
\hline \multicolumn{4}{|c|}{ Abbreviations } \\
\hline$A_{w}$ & water activity & Qst & net isosteric heat of sorption $\left(\mathrm{kJ} \mathrm{mol}{ }^{1}\right)$ \\
\hline$c$ & water concentration $\left(\mathrm{kg} \mathrm{m}^{3}\right)$ & $R$ & universal gas constant $\left(\mathrm{J} \mathrm{mol}{ }^{1} \mathrm{~K}^{1}\right)$ \\
\hline $\mathrm{db}$ & dry basis & $T$ & absolute temperature $(\mathrm{K})$ \\
\hline$D_{f}$ & apparent diffusion coefficient $\left(\mathrm{m}^{2} \mathrm{~s}^{1}\right)$ & $T$ & isokinetic temperature $(\mathrm{K})$ \\
\hline ERH & equilibrium relative humidity (\%) & $T_{h m}$ & harmonic mean temperature $(\mathrm{K})$ \\
\hline$F$ & water flux, Fick's law, $\left(\mathrm{kg} \mathrm{m}^{2} \mathrm{~s}^{1}\right)$ & $X$ & relative humidity (\%) \\
\hline$k_{p}$ & $\begin{array}{l}\text { affinity between vapour solvent molecules and solid } \\
\text { sites (ENSIC model) }\end{array}$ & $x$ & length $(\mathrm{m})$ \\
\hline$k_{s}$ & affinity between vapour solvent molecules and adsorbed & \multicolumn{2}{|c|}{ Greek symbols } \\
\hline & solvent molecules (ENSIC model) & $\alpha$ & constant \\
\hline$m\left(a_{i}\right)$ & mass of spherical particles of radius $a_{i}(\mathrm{~g})$ & $\Delta G$ & change in Gibb's free energy $\left(\mathrm{J} \mathrm{mol}^{1}\right)$ \\
\hline$M_{t}$ & water content $(\% \mathrm{db})$ at time $\mathrm{t}$ & $\Delta H$ & change in enthalpy $\left(\mathrm{J} \mathrm{mol}^{1}\right)$ \\
\hline$M_{e q}$ & water content at the equilibrium & $\Delta \mathrm{H}_{\mathrm{imm}}$ & change in immersion enthalpy $\left(\mathrm{J} \mathrm{mol}^{1}\right)$ \\
\hline$n$ & number of isotherms at different temperatures & $\Delta S$ & change in specific entropy $\left(\mathrm{J} \mathrm{mol}{ }^{1} \mathrm{~K}^{1}\right)$ \\
\hline$P$ & water vapour pressure exerted by the sample (Pa) & $\varphi$ & volumetric fraction of adsorbed solvent (ENSIC model) \\
\hline$P^{0}$ & vapour pressure of pure water at a given temperature & & \\
\hline & $(\mathrm{Pa})$ & $\theta$ & liquid solid contact angle $\left(^{\circ}\right)$ \\
\hline
\end{tabular}

- Thermodynamics properties of hydration, including Gibbs free energy, enthalpy and entropy.

Sorption isotherms and isosteric heat of sorption of cereal based products are essential for the design, modelling and optimi sation of many processes such as drying, aeration and storage. There exist also relationships between the thermodynamic func tions of gas solid adsorption and liquid solid immersion which are of the utmost importance for the wetting and hydration steps of many manufacturing processes. The knowledge of thermody namic functions could provide information on the affinity between water and the cereal product including the binding forces, the water molecules, their spatial arrangement, and the spontaneity of the sorption process.

From sorption isotherms, water adsorption capacity and hydra tion stabilisation time have been measured. By modelling sorption isotherms trends, the type of solid liquid interactions can be esti mated. Several models has been developed in relation with the de sired application. For example, the structural state of water sorbed can be assessed by the GAB model (Dural and Hines, 1993); the affinity of water vapour molecules from solid sites can be esti mated by the ENSIC Model (Favre et al., 1996). From sorption iso therms, apparent diffusion coefficient of water within the grain can be calculated by resolution of the second Fick's law (Levoguer, 1997). Finally, under temperature and hydration conditions, phys ico chemical and/or structural modifications of the solid can be evaluated by the amplitude of the hysteresis: the difference be tween adsorption and desorption isotherms (Chung and Pfost, 1967; Sun and Woods, 1993; Dural and Hines, 1993).

Hydration thermodynamics properties can be determined by different methods: immersion, isosteric method (gas adsorption), gas chromatography or calorimetry. The values of thermodynamics functions are specific of the method employed. However, thermo dynamics properties, irrespective of the method employed, can be used to predict the spontaneity of the reaction, the energy to be supplied and the energy released by the reaction.

Internal hydration properties depend mainly on the physico chemical properties of the solid. Water absorption capacity is influ enced essentially by biochemical composition, porosity and rough ness (liquid retention in pores). Hydration kinetics depends on solid wetting properties, specific surface area and porosity of the solid. Furthermore, physico chemical (components dissolution, irreversible water adsorption) or structural (porosity, specific sur face area) solid properties can be altered due to hydration coupled

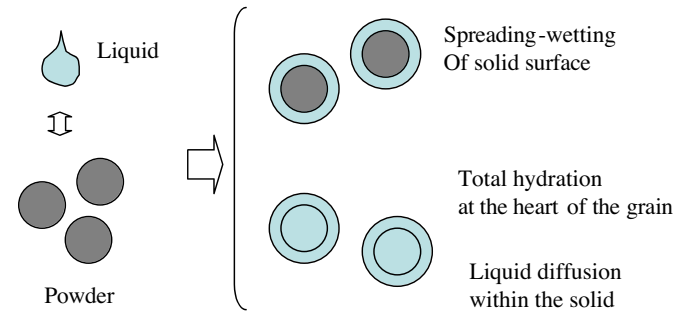

Fig. 1. Powder reactivity under hydration conditions (surface and internal reactivities)

with the effect of temperature (Dural and Hines, 1993; Chung and Pfost, 1967; Bell and Labuza, 2000). Eventually, hydration proper ties can be modified as a function of temperature.

In this paper, sorption isotherms determination and other experiments, complementary to those previously described (Hébr ard et al., 2003) are presented.

These characterisations will be used to a more detailed descrip tion of semolina/water interactions mechanisms which, in turn, can be used for a better control of the hydration step in agglomer ation process for making pasta or couscous.

\section{Materials and methods}

\subsection{Raw material}

Superior quality industrial semolina A (0 $630 \mu \mathrm{m})$ has been used both in its entirety and sub divided into three sieve fractions: A1 $(0200 \mu \mathrm{m}), A 2(200400 \mu \mathrm{m})$ and A3 $(400630 \mu \mathrm{m})$. It has a density of $1450 \mathrm{~kg} \mathrm{~m}^{3}$ and a specific surface area of $0.05 \mathrm{~m}^{2} \mathrm{~g}{ }^{1}$, no intragranular porosity could be detected. The physicochemical, biochemical and structural properties of semolina and its sub frac tions are reported in Table 1 . Two populations of starch granules (which differ in shape and size) are bound by a gluten matrix. Small spherical starch granules $(<10 \mu \mathrm{m})$, are distinct from large and oval ones, of size between $20 \mu \mathrm{m}$ and $40 \mu \mathrm{m}$. Occasionally, aleurone layer cells, about $40 \mu \mathrm{m}$ in size, with an alveolar struc ture, were observed. The surface ratio of this component is low, about $2 \%$ of surface area. This characterisation has been previously described (Hébrard et al., 2001). 


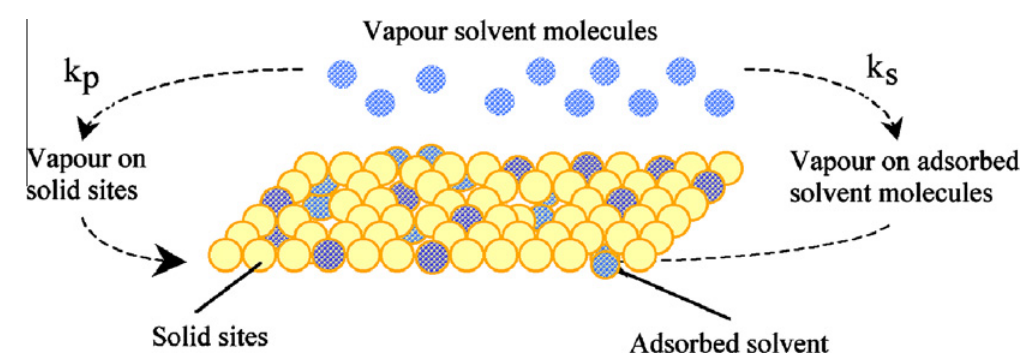

Fig. 2. Schematic representation of vapour solvent molecules affinity for solid sites and for adsorbed solvent molecules " ENSIC model».

Table 1

Physico-chemical and biochemical characterisation of durum wheat semolina and its sub-fractions.

\begin{tabular}{|c|c|c|c|c|}
\hline & \multirow{2}{*}{$\begin{array}{l}\text { Semolina }(\mu \mathrm{m}) \\
\mathrm{A}(0-630)\end{array}$} & \multicolumn{3}{|c|}{ Sub-fractions of semolina $[\mu \mathrm{m}[$} \\
\hline & & A1 $(0-200)$ & A2 (200-400) & A3 (400-630) \\
\hline Average diameter $d_{50}(\mathrm{~m})$ & 300 & 157 & 325 & 470 \\
\hline Span: $\left[\left(d_{90}-d_{10}\right) / d_{50}\right]$ & 0.9 & 1.2 & 0.7 & 1.3 \\
\hline \multicolumn{5}{|l|}{ Composition (\% db) } \\
\hline Starch & 86.1 & 83.3 & 85.6 & 86.9 \\
\hline Damaged starch & 5.9 & 9.3 & 5.0 & 4.6 \\
\hline Proteins & 13.5 & 15.4 & 14.1 & 13.0 \\
\hline Insoluble proteins in SDS & 6.7 & 5.9 & 7.8 & 6.9 \\
\hline Total pentosans & 1.7 & 1.9 & 1.6 & 1.3 \\
\hline Soluble pentosans & 0.12 & - & 0.13 & 0.12 \\
\hline Free lipids & 1.4 & 2.4 & 1.5 & 1.1 \\
\hline Reducing carbohydrates & 0.7 & 1.5 & 0.7 & 0.5 \\
\hline Ash & 1.2 & 1.7 & 1.3 & 0.6 \\
\hline
\end{tabular}

\subsection{Hydration properties}

Hydration properties have been determined by gravimetric methods using an experimental method described below and by using specific models to exploit sorption isotherms. Thermody namics hydration properties have also been measured by mixing microcalorimetry.

2.2.1. Measurement of hydration properties by gravimetric method Adsorption data were measured gravimetrically using an auto mated Dynamic Vapour Sorption system (DVS 1000 Surface Measurement Systems ${ }^{\circledR}$, UK). The sample, $2837 \mathrm{mg}$ previously dried, was uniformly spread in a small dry cup, then placed in the microbalance. After a pre equilibration at ERH $0 \%$, relative humid ity varied by $5 \%$ increments between $0 \%$ and $95 \%$ under a nitrogen flow of $375 \mathrm{~s} \mathrm{~cm}^{3}$ (standard cubic centimetres). The progression to the next stage occurred by a change in mass lower than $0.002 \%$, with a minimum time of $10 \mathrm{~min}$ and a maximum of $360 \mathrm{~min}$. The variation of mass of the sample as a function of was recorded at a given temperature.

\subsubsection{Solid water affinity: application of the ENSIC model}

ENSIC (Engaged Species Induced Clustering) model has been developed by considering sorption as an anisotropic mechanistic phenomenon from a simple mechanistic approach in which solvent molecules can be adsorbed on solid sites or on already adsorbed solvent molecules (Favre et al., 1996). According to the values of $k_{p}$ and $k_{s}$, vapour solvent molecules will be sorbed preferentially on solid sites if $k_{s}<k_{p}$ or on adsorbed solvent molecules if $k_{s}>k_{p}$. This theory can be applied to numerous polar or non polar polymers.

ENSIC Model : $\quad \varphi \frac{k_{p}}{\left(k_{s} k_{p}\right)}\left(\begin{array}{lll}\left.e^{\left(k_{s}\right.} k_{p}\right) A_{w} & 1\end{array}\right)$.

\subsubsection{Diffusion coefficient}

The diffusion coefficient at a given ERH $(X \%)$ can be evaluated after a $5 \%$ variation of ERH (from $X \%$ to $X+5 \%$ ) in a single step using the same experimental protocol of the DVS ${ }^{\circledR}$ previously described. The sample should be uniformly spread in the cup in the form of a thickness film; its thickness can be measured either by a calliper rule or from sample mass, density and the cup volume.

The Fick's second law (Eq. (2)) can be used to calculate diffusion either in spherical particles (Becker, 1959) or in polymers film (Crank, 1976). For this application, the diffusion coefficient was calculated from Crank equation (Eq. (4)) since we do not determine the diffusion coefficient of a single semolina particle but of a group of grains comparable to a film. This film can be defined by its thick ness $(e)$ and its porosity, equivalent to the inter granular porosity of semolina ( $\varepsilon_{\text {inter }} A \quad 0.2$ ). This diffusion coefficient corresponds to the sum of diffusion between semolina grains and within a grain.

The apparent diffusion coefficient of vapour water into semo lina powder is obtained at a given relative humidity (X\%) by plot ting $\ln \left(\begin{array}{ll}M_{e q} & M_{t}\end{array}\right)$ as a function of time $t$. The diffusion coefficient at a given relative humidity $(X \%)$ is calculated from the slope of the linear part of this curve.

Second Fick's law : $\quad F \quad D_{f} \cdot \frac{\delta c}{\delta x}$

Diffusion in spherical particles:

$\frac{M_{t}}{M_{\infty}} \quad 1 \quad \frac{6}{\pi^{2}} \sum_{i} m(a i) \sum_{n 1}^{\infty} \frac{1}{n^{2}} \exp \left(\frac{\pi^{2} \cdot n^{2} \cdot D_{f}}{(a i)^{2}} t\right)$

Diffusion in a film of polymer:

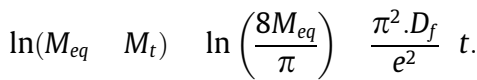




\subsubsection{Thermodynamics sorption properties}

From sorption isotherms at different temperatures $(2 \mathrm{mini}$ mum), thermodynamics sorption properties can be calculated. Gibbs free energy $(\Delta G)$, enthalpy $(\Delta H)$ and entropy $(\Delta S)$ are the main thermodynamics functions which are linked by the Gibbs Helmoltz relation:

Gibbs Helmoltz equation: $\Delta G \quad \Delta H \quad T \quad \Delta S$.

Gibbs free energy $(\Delta G)$ is the driving force at constant temper ature and pressure. A change in free energy is generally coupled with enthalpy and entropy changes. The sign of $\Delta G$ informs about the spontaneity of the reaction. If $\Delta G<0$, the reaction is spontane ous. The alteration of water binding mechanisms can be identified by a change in the slope of Gibbs free energy $(\Delta G)$ plotted versus water content of the sample (EMC) as demonstrated by Lagoudaki et al. (1993).

Enthalpy $(\Delta H)$ is the heat released by hydration at constant pressure $(\Delta H \quad$ Qst). It informs about binding energy, intermolec ular strength developed between the solvent (binder) and the adsorbent surface (or binding sites) and between the solvent and adsorbed molecules. The nature, homogeneity and heterogeneity of adsorbent surface can be characterised by the plot of the "heat curve" representing the evolution of isosteric heat of sorption (Qst) versus binder ratio (Dural and Hines, 1993). Enthalpy change provides a measure of the energy variations occurring on mixing water molecules with sorbent during sorption process.

Entropy $(\Delta S)$ defines the degree of order or randomness existing in the water sorbent system and helps interpretation of process such as dissolution, crystallisation, wetting and swelling (McMinn and Magee, 2003). Entropy is related to degrees of freedom of the adsorbent; it is a measurement of the disorder, the various micro scopic and structural states. According to the second law of ther modynamics, the phenomena are reversible if the entropy variation equals zero. A decrease of entropy means an increase in the structural states of adsorbed molecules.

A relation between enthalpy and entropy, defined as an enthal py/entropy compensation, was defined by Everett (1950) postulat ing that $\Delta H$ and $\Delta S$ are independent of temperature. An enthalpy/ entropy compensation exists if the correlation degree between $\Delta H$ and $\Delta S$ is good and if $T_{\beta} \neq T_{h m}$. The following equation by Leffler and Grunwald (1963) gives this correlation.

Leffler and Grunwald equation (1963): $\quad \Delta H \quad T_{\beta} \Delta S+\alpha$

$T_{\beta}$ and $\alpha$ were calculated by linear regression from data enthalpy versus entropy.

With $T_{h m}$, the harmonic mean of the temperatures defined as: $T_{h m}=\frac{n}{\sum_{1}^{n}(1 / T)}$

The sorption phenomenon is controlled by enthalpy if $T_{\beta}>T_{h m}$, otherwise it is controlled by entropy. On a wide range of relative humidity, depending on the product, the enthalpy/entropy com pensation can present both tendencies. Once enthalpy/entropy compensation is checked, this relation can be used for modelling the influence of temperature on sorption isotherms by a 2 param eter equation:

Aguerre et al. equation (1986): $\quad \ln \left(\frac{P}{P^{0}}\right) \quad \frac{\Delta H}{R}\left(\begin{array}{ll}\frac{1}{T} & \frac{1}{T_{\beta}}\end{array}\right)$.

The enthalpy entropy compensation theory has been widely investigated for many different physical and chemical processes (Madamba et al., 1996), and has been checked for numerous prod ucts such as wood, rice, wheat and corn (Aguerre et al., 1986; Resio and Aguerre, 1999; Tolaba et al., 1997; Koumoutsakos and Avram idis, 1999; Gabas et al., 2000).

From sorption isotherms at different temperatures, the semi log plot of water activity $\left(\begin{array}{ll}w & P / P^{0}\end{array}\right)$ versus $(1 / T)$ for a constant quantity

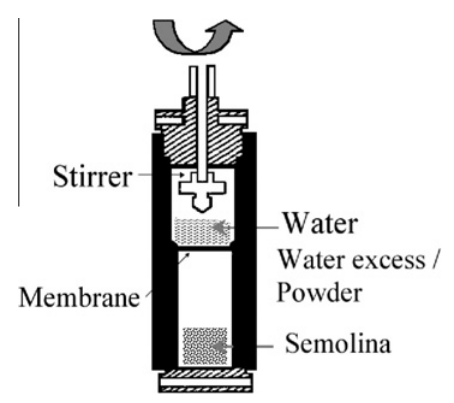

Fig. 3. Solid-liquid contact in mixing microcalorimeter.

of sorbed water at different temperatures correspond to a straight line with:

- The isosteric heat of sorption (Qst $\Delta H$ ) determined from the slope (Clausius Clapeyron, 8 or Everett equations, 9).

- The entropy $(\Delta S)$ obtained from the intercept at the origin (Everett equation, 9).

- The free energy $(\Delta G)$ calculated from the Gibbs Helmoltz Eq. (5).

Clausius Clapeyron equation: $\frac{Q s t}{R} \quad \frac{d \ln \left(P / P^{0}\right)}{d(1 / T)} \quad \Delta H$

Everett equation [1950, a]:

$\ln \left(\frac{P}{P^{0}}\right) \quad \ln (A w) \quad\left(\frac{\Delta H}{R \cdot T}\right) \quad\left(\frac{\Delta S}{R}\right)$

$\Delta G \quad R \cdot T \ln \left(\frac{P}{P^{0}}\right)$

\subsubsection{Thermodynamics hydration properties by mixing calorimetry}

Mixing microcalorimetry technique can be used to measure the hydration energy under mixing conditions by immersion of a pow der in a liquid. Temperature and exterior thermal exchanges are precisely controlled. A C80 D microcalorimeter $\left(\right.$ Setaram ${ }^{\circledR}$ ) equipped with a membrane mixing cell composed of 2 parts separated by a metal membrane was used (Fig. 3). In this specific application, water was placed in the higher part of the cell and semolina in the lower part.

Approximately, $100 \mathrm{mg}$ of semolina, exactly weighed, were mixed with $1000 \mathrm{mg}$ of distilled water at a specific temperature. Immersion enthalpy $\left(\Delta H_{\text {imm }}\right)$ of semolina $\mathrm{A}$ and its sub fractions in water were measured at $25^{\circ} \mathrm{C}$. The effects of hydration temper ature and wetting liquid were investigated on immersion enthalpy of semolina A. Duplicate measurements were made to estimate the errors in the experimental method.

\section{Results: hydration properties}

The uptake and the kinetics of water vapour sorption of semo lina $\mathrm{A}$ and its sub fractions were previously determined at $25^{\circ} \mathrm{C}$, $35^{\circ} \mathrm{C}$ and $45^{\circ} \mathrm{C}$ (Hébrard et al., 2003). Alteration due to hydration of semolina A was estimated by making several cycles of adsorp tion/desorption. Physico chemical and structural properties had not been modified by hydration at any of the three tested temper atures. In addition, these authors did not identify any significant effect of particle size on the water adsorption kinetics of durum wheat semolina. 
Table 2

Solid-liquid interactions parameters calculated by «ENSIC» model.

\begin{tabular}{lllll}
\hline & Semolina $(\mu \mathrm{m})$ & \multicolumn{3}{l}{ Sub-fractions of semolina A $(\mu \mathrm{m})$} \\
\cline { 3 - 5 } & $\mathrm{A}[0-630[$ & $\mathrm{A} 1(0-200)$ & $\mathrm{A} 2(200-400)$ & $\mathrm{A} 3(400-630)$ \\
\hline$k_{s}$ & 0.95 & 0.90 & 0.90 & 1.00 \\
$k_{p}$ & 0.13 & 0.14 & 0.14 & 0.13 \\
$k_{s} / k_{p}$ & 7.30 & 6.40 & 6.4 & 7.70 \\
$R^{2}$ & 0.997 & 0.996 & 0.996 & 0.97 \\
\hline
\end{tabular}

\subsection{Affinity of water vapour for solid sites (gravimetry)}

Affinity coefficients between vapour molecules and solid sites $\left(k_{p}\right)$ and between vapour solvent molecules and adsorbed solvent molecules $\left(k_{s}\right)$ have been estimated by application of ENSIC model to sorption isotherms. For semolina A and its sub fractions, at $25{ }^{\circ} \mathrm{C}$, vapour solvent molecules are attached preferentially to the adsorbed solvent molecules rather than to the solid sites $\left(k_{s} \gg k_{p}\right.$; $k_{s} \approx 67 k_{p}$ ) as shown in Table 2 .

\subsection{Diffusion coefficient at $25^{\circ} \mathrm{C}$ (gravimetry)}

Apparent diffusion coefficient of water vapour in a thin film of semolina (2.685 mm) was calculated from Crank (Eq. (4)). This dif fusion coefficient is the sum of diffusion between semolina grains and diffusion within a grain. For the evolution of the apparent diffusion coefficient versus relative humidity (Fig. 4), 3 steps can be identified with the increase of relative humidity:

- For ERH $<30 \%$, the diffusion coefficient decreases.

- For $30 \%<\mathrm{ERH}<70 \%$, the diffusion coefficient increases.

- For ERH $>70 \%$, the diffusion coefficient decreases.

The relative humidity describing these 3 stages correspond to the different types of liquid solid interactions identified from the evolution of water vapour adsorbed versus relative humidity and to the 3 phases described for the time required to reach the mass stabilisation at a given relative humidity (Hébrard et al., 2003).

At ERH 95\%, the diffusion coefficient of water in a thin film of semolina is about $1.2 \times 10^{10} \mathrm{~m}^{2} \mathrm{~s}{ }^{1}$. This value is in good agree ment with several other published work on durum wheat semo lina. Kang and Delwiche (1999) studied the water uptake kinetics of durum wheat samples at $22{ }^{\circ} \mathrm{C}$ and found a diffusion coefficient of $0.73 \times 10^{10} \mathrm{~m}^{2} \mathrm{~s}{ }^{1}$ by numerical modelling of the moisture dif fusion using a finite element model. Kratzer (2007) proposed a method to estimate a diffusion coefficient of water in durum endo sperm by using numerical simulation based on a diffusion model. The diffusion coefficients were found $0.43 \times 10^{10 \mathrm{~m} 2 \mathrm{~s} 1}$ and $1.0 \times 10^{10} \mathrm{~m}^{2} \mathrm{~s}^{1}$, with an overall mean of $0.76 \times 10^{10} \mathrm{~m}^{2} \mathrm{~s}^{1}$. There is, however, a significant difference with the diffusion coefficient of water in bread wheat flour determined by Roman
Guttierrez (2002): $4.1 \times 10{ }^{10} \mathrm{~m}^{2} \mathrm{~s}^{1}$. This difference between diffusion coefficient of water within semolina and bread wheat flour can be attributed either to the nature of the product or to the experimental protocol (thickness and cup used). In addition, this coefficient was determined from sorption isotherms by con sidering diffusion in spherical particles.

\subsection{Thermodynamic hydration properties}

Thermodynamics hydration properties have been determined by sorption isotherms and by mixing calorimetry $\left(\Delta H_{i m m}\right)$.

\subsubsection{Thermodynamics sorption properties}

Thermodynamics sorption properties of semolina $A$ have been calculated from sorption isotherms at $25^{\circ} \mathrm{C}, 35^{\circ} \mathrm{C}$ and $45^{\circ} \mathrm{C}$. Tem perature do not alter water uptake whereas the stabilisation time is reduced. On the other hand, physico chemical and structural properties of the solid are not irreversibly altered under hydration and temperature $\left(25^{\circ} \mathrm{C}\right.$ and $45^{\circ} \mathrm{C}$ ) effects (Hébrard et al., 2003).

For each water content of the grain, water activity is deter mined at $25^{\circ} \mathrm{C}, 35^{\circ} \mathrm{C}$ and $45^{\circ} \mathrm{C}$ (Table 3 ) and the linear relation: $\ln \left(A_{w}\right) \quad f(1 / T)$ can be plotted (Fig. 5). The isosteric heat and the enthalpy of sorption (Qst $\Delta H$ ) are obtained from the slope of the straight line $(\mathrm{Qst} / R)$. The entropy of sorption is calculated from the intercept at the origin $(\Delta S / R)$. Gibbs free energy $(\Delta G)$ is obtained from Gibbs Helmoltz Eq. (5).

The variation of enthalpy of sorption and entropy versus water content presents the same trend (Figs. 6 and 7). In absolute value, both the enthalpy and entropy of sorption are high at low water content and reach a minimum with the increase of water content. As for $\Delta H$, this trend is supported by the fact that as moisture con tent increases, the attraction forces of water molecules by semolina decrease. The $\Delta S$ values also showed a strong dependence on moisture content. This entropy decrease during sorption could be attributed to a better arrangement of the sorbed water molecules, particularly at low moisture contents.

\subsubsection{Hydration of semolina is an exothermic phenomenon $(\Delta H<0)$}

These curves give information about the solid liquid interac tions, entropy representing the disorder (Dural and Hines, 1993). First adsorption occurs on the most active sites, the interaction en ergy is the highest. During the formation of the first layer (water content $<7 \% \mathrm{db}$ ), isosteric heat and enthalpy decrease to a mini mum resulting in the progressive saturation of the solid sites. Bind ing energy between water and solid sites and structural state of water molecules decrease. Thus, for multilayer adsorption, for a water content $>7 \% \mathrm{db}$, the isosteric heat of sorption is minimal and correspond to the water condensation heat $\left(\Delta H \approx L_{V}\right.$ $\left.2480 \mathrm{~J} \mathrm{~mol}^{1}\right)$; then structural state of water molecules is minimal.

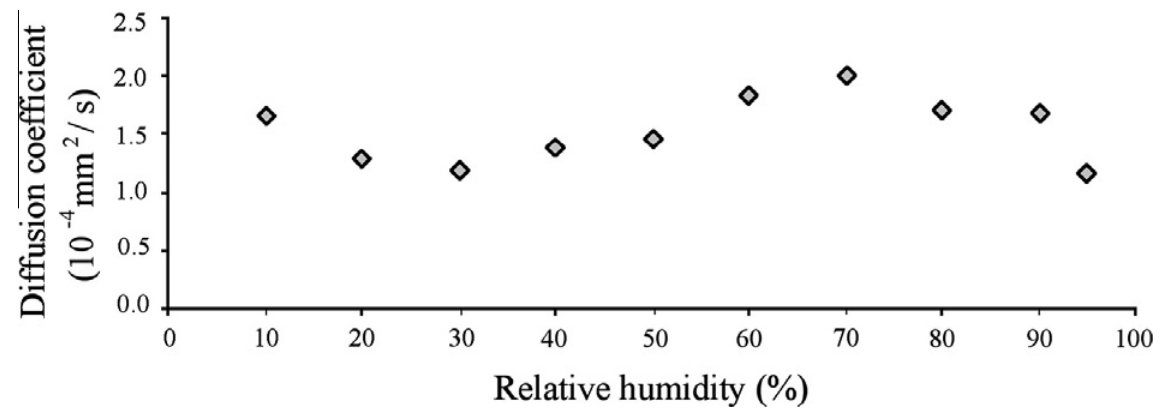

Fig. 4. Variation of the apparent diffusion coefficient at $25^{\circ} \mathrm{C}$ in a semolina film of small thickness $(2.685 \mathrm{~mm})$. 
Table 3

Water activity in relation with different temperatures at a given water content.

\begin{tabular}{lllll}
\hline & \multicolumn{4}{l}{ Water content $(\% \mathrm{db})$} \\
\cline { 2 - 5 } & $2.5 \%$ & $5 \%$ & $7.5 \%$ & $20 \%$ \\
\hline$A_{w}$ at $25^{\circ} \mathrm{C}$ & 0.119 & 0.257 & 0.401 & 0.899 \\
$A_{w}$ at $35^{\circ} \mathrm{C}$ & 0.104 & 0.245 & 0.398 & 0.906 \\
$A_{w}$ at $45^{\circ} \mathrm{C}$ & 0.086 & 0.226 & 0.380 & 0.851 \\
\hline
\end{tabular}

As explained in Section 2.2.4 an entropy / enthalpy compensa tion can be established (Fig. 8) as the correlation degree between $\Delta H$ and $\Delta S$ is good $\left(R^{2} \quad 0.995\right)$ and $T_{\beta} \neq T_{h m}$. On the other hand, since $T_{\beta}<T_{h m}\left(T_{\beta} \quad 244 \mathrm{~K}\right.$ and $\left.T_{h m} 303 \mathrm{~K}\right)$ on the wide range of relative humidity, the sorption is rather controlled by entropy (structural state of water molecules) than enthalpy (binding en ergy between water and sorption sites).

Eventually, from the evolution of Gibbs free energy as a function of the water content (Fig. 9), 2 discontinuous points can be identi fied; they represent water binding mechanism modifications. The first point $(5 \% \mathrm{db})$ is close to the monolayer value obtained by Lagoudaki et al. (1993) showed for spaghetti. The second point (water content $\approx 15 \% \mathrm{db}$ ) characterises the alteration of water binding state from water closely tied to free water. The effects have been observed at the 4 temperatures studied: $15^{\circ} \mathrm{C}, 20^{\circ} \mathrm{C}, 35^{\circ} \mathrm{C}$ and $45^{\circ} \mathrm{C}$.

These characterisations of thermodynamics hydration proper ties of semolina by water give more detailed information about sorption mechanisms and about thermodynamics of mono and multi layers formation.

\subsection{Thermodynamics hydration properties by mixing calorimetry}

Immersion enthalpy $\left(\Delta H_{i m m}\right)$ of semolina $A$ and its sub fractions in water have been determined by mixing calorimetry at $25^{\circ} \mathrm{C}$. The influence of immersion temperature and liquid of hydration (per fect wetting liquid: hexane) have been investigated. Furthermore, we have characterised the immersion enthalpy of the main compo nents of semolina, starch and gluten, unknown to date.

Immersion of semolina in water is an exothermic reaction $\left(\Delta H_{i m m}<0\right)$. Deviation between several analyses has been ob served, with a gap between 2 measurements up to $20 \%$. (example: for semolina A at $40{ }^{\circ} \mathrm{C}: \Delta H_{i m m} 1 \quad 6,5$ and $\Delta H_{i m m} 2 \quad 8 \mathrm{Jg}{ }^{1} \mathrm{db}$ ). Considering the method inaccuracy, the size of semolina grains does not significantly affect immersion enthalpy; so, immersion enthalpy of semolina is about 5 to $8 \mathrm{Jg}{ }^{1} \mathrm{db}$ (Table 4).

Immersion enthalpy (Table 5) is affected neither by tempera ture $\left(25^{\circ} \mathrm{C}\right.$ and $\left.40^{\circ} \mathrm{C}\right)$ nor by surface energy of liquid hydration (perfect wetting liquid: hexane). Immersion enthalpy of starch and gluten are different. Starch, having better wetting properties than gluten (Roman Guttierrez, 2002), presents a higher immer sion enthalpy. From these comparisons, it seems that immersion enthalpy is not only correlated to wetting energy, it should also been considered energy for:

- Bringing into contact water molecules and solid surface;

- Diffusion of water within the grain;

- Homogenisation of the mixture.

$\Delta H_{\text {imm }}$ starch $\left(17 \mathrm{Jg}{ }^{1} \mathrm{db}\right)<\Delta H_{\text {imm }}$ gluten $\left(2 \mathrm{Jg}{ }^{1} \mathrm{db}\right)$

Wetting contact angle $(\theta)$ : starch/water $\left(\begin{array}{ll}\theta & 38^{\circ}\end{array}\right)>$ gluten/water

$\left(\begin{array}{ll}\theta & 85^{\circ}\end{array}\right)$ (Roman Guttierrez, 2002).

In conclusion, hydration of semolina grains under mixing condi tions is an exothermic reaction:

- Independent on the immersion temperature in the range $2540^{\circ} \mathrm{C}$ and on the surface energy of the hydration liquid, if the liquid wets the solid.

- Depending on biochemical composition: important differences between starch and gluten have been observed. However, bio chemical differences in function of semolina grain size are not sufficient to affect hydration energy.

Hydration energy seems only to be influenced by energy for bringing into contact water molecules and solid surface and for homogenisation of the mixture; diffusion of water within the grain seems to be poor energy consuming.

\section{Discussion}

For semolina, a product complex due to its physico chemical properties, biochemical composition and surface properties, (Hébr ard et al., 2001, 2003), we tried to explain water uptake mecha nisms by hydration properties determined from sorption isotherms and from thermodynamic hydration properties under mixing conditions. Hydration by vapour or liquid water is an exo thermic reaction $\left(\Delta H_{i m m}\right.$ and $\left.\Delta H<0\right)$. Sorption isotherms show that several additional layers of water are adsorbed successively. The multilayer formation can be described by water diffusion with in the grain and by solid liquid interaction energy more than water uptake and hydration kinetics. For ERH $<20 \%$, during the for mation of the monolayer (for a water content about $0.06 \mathrm{~kg}$ water/ $\mathrm{kg} \mathrm{db}$ ) the stabilisation time, short at very low ERH (10\%), increases while the diffusion coefficient of liquid within the solid decreases. First, adsorption takes place on the more active sites of the solid giving rise to the highest interaction energy. With the increase of

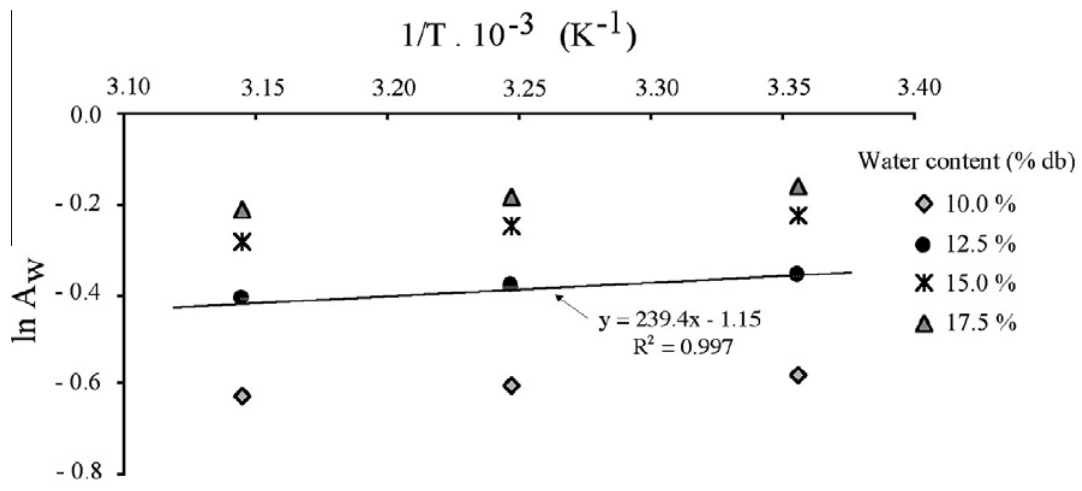

Fig. 5. $\ln \left(A_{w}\right)$ as a function of $(1 / T)$ or different water content of semolina: determination of the slope $(-\Delta H / R)$ and of the intercept at the origin $(-\Delta S / R)$. 


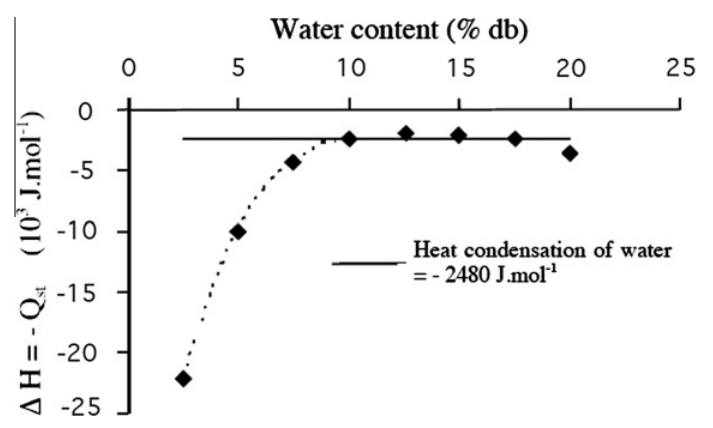

Fig. 6. Variation of enthalpy $(\Delta H=-\mathrm{Qst})$ as a function of water content.

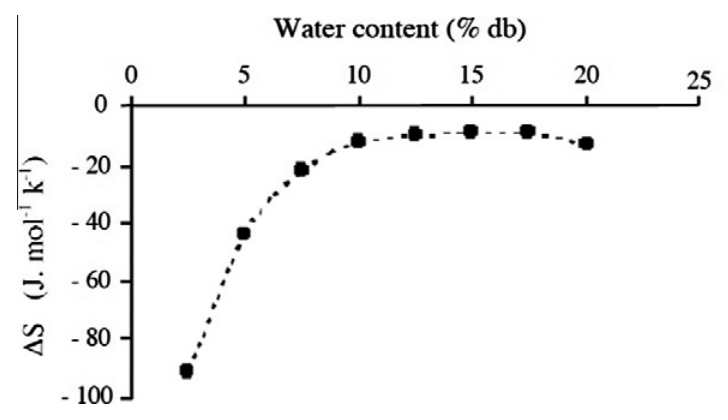

Fig. 7. Variation of entropy $(\Delta S)$ as a function of water content.

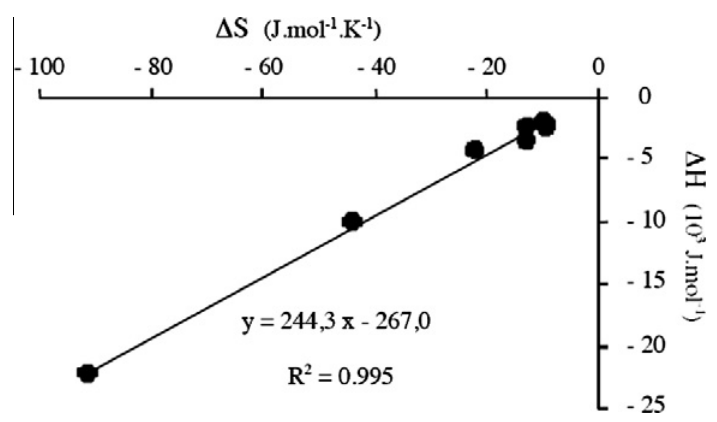

Fig. 8. Enthalpy/entropy relation; $T_{\beta} \neq T_{h m}$ and $T_{\beta}<T_{h m}$. $\left(T_{\beta}=244 \mathrm{~K}\right.$ et $\left.T_{h m}=303 \mathrm{~K}\right)$.

Table 4

Immersion enthalpy in water under mixing conditions at $25^{\circ} \mathrm{C}( \pm 20 \%)$.

\begin{tabular}{|c|c|c|c|c|c|c|}
\hline \multirow[b]{3}{*}{ Immersion enthalpy $\left(\mathrm{Jg}^{1} \mathrm{db}\right) \pm 20 \%$} & \multirow{3}{*}{$\begin{array}{l}\text { Semolina }(\mu \mathrm{m}) \\
\text { A [0-630[ } \\
-6.7\end{array}$} & \multicolumn{3}{|c|}{ Sub-fractions of semolina $A(\mu \mathrm{m})$} & \multicolumn{2}{|c|}{ Semolina components } \\
\hline & & A1 $(0-200)$ & A2 $(200-400)$ & A3 (400-630) & Starch & Gluten \\
\hline & & -8.6 & -8.6 & -8.2 & -17.2 & -2.0 \\
\hline
\end{tabular}

Table 5

Influence of temperature and surface energy of the hydration liquid on immersion enthalpy for semolina $\mathrm{A}( \pm 20 \%)$.

\begin{tabular}{llll}
\hline & Water $\left(\right.$ at $\left.25^{\circ} \mathrm{C}\right) \gamma_{1}=72 \mathrm{mN} / \mathrm{m}$ & Water $\left(\right.$ at $\left.40{ }^{\circ} \mathrm{C}\right)$ & Hexane $\left(\right.$ at $\left.25^{\circ} \mathrm{C}\right) \gamma_{1}=20 \mathrm{mN} / \mathrm{m}$ \\
\hline Immersion enthalpy $\left(\mathrm{Jg}^{1} \mathrm{db}\right) \pm 20 \%$ & -6.7 & -5.5 & -8.3 \\
\hline
\end{tabular}

ERH, solvent/solid interaction energy and structural state of water molecules (entropy), high at low ERH, decrease to a minimum.

For $20 \%<\mathrm{ERH}<70 \%$, during the formation of additional layers on the resultant monolayer, the diffusion coefficient increases which explains the increase of water content with a constant stabilisation time. The energy for solvent/solid interactions and structural state of water molecules are minima and remain con stant during multilayer formation. Hydration enthalpy is equiva lent to water condensation heat.

For ERH $>70 \%$, solvent/solid interaction energy and structural state of water molecules are minimal, explaining why the water sorbed is weakly linked and quite mobile and stabilisation time is long.

From the evolution of Gibbs free energy $(\Delta G)$ versus water content, the modification of water vapour binding mechanisms from solid sites (monolayer formation) to sorbed water molecules (multilayer formation) has been identified. The linear relation be tween entropy and enthalpy for $0<\mathrm{ERH}<95 \%$ shows that sorption of water vapour is rather controlled by structural state of water molecules (entropy) than by the binding energy between water and solid sites (enthalpy).
Sorption energy changes in relation with the solid water content can be interpreted by affinity coefficient of water vapour molecules for solid sites $\left(k_{p}\right)$ and for water adsorbed molecules $\left(k_{s}\right)$. The higher the affinity, the lower the sorption energy required. Since $k_{p}<<k_{s}$, the affinity of water vapour molecules for solid sites is weaker than for water adsorbed molecules. Thus, at low ERH, for monolayer formation, binding energy of water molecules to solid sites is higher than for multilayer formation; this also explains the decrease in binding energy progressively with monolayer sat uration. Once the monolayer is formed, sorption energy is minimal and remains constant.

Sorption enthalpy is equivalent to water condensation heat when the monolayer is formed and immersion enthalpy under mixing is relatively low (about $58 \mathrm{Jg}^{1} \mathrm{db}$ ). It seems that when the particle surface is hydrated (vapour condensation or wetting by liquid water), liquid components interactions as well as diffusion of water within the grain and internal hydration are less energy consuming. So, hydration energy of semolina by liquid or vapour water could be assimilated to the energy required to bring into contact water and grain surface and to homogenise the mixture. For starch and gluten, the main components of 
semolina, the determination of their thermodynamic sorption properties would be useful for the interpretation of the values of immersion energy.

\section{Conclusion}

In this study, the hydration properties of semolina have been characterised: sorption isotherms and diffusion coefficients have been determined by gravimetric method.

The immersion enthalpy of the semolina and its main sub com ponents, starch and gluten have been measured by mixing micro calorimetry. Hydration thermodynamic functions, Gibbs free energy, enthalpy and entropy, were calculated and it was found that hydration is an exothermic reaction.

The enthalpy entropy compensation theory could be success fully applied to water adsorption behaviour of semolina. The mois ture adsorption of semolina, appeared to be an entropy controlled process.

The diffusion coefficient determination led to evaluate the sta bilisation time of water within the solid. Being high at low relative humidity, the diffusion coefficient decreases during progressive saturation of solid sites.

The hydration energy needed to generate contact between water and grain surface and for mixture homogenisation, was found to be low.

These characterisations of interactions between water and sem olina allow a better understanding of the mechanisms of water uptake by semolina during the wetting and hydration step in cous cous or pasta manufacturing process. Following this study, it would be interesting to characterise agglomeration properties un der hydration and mixing conditions.

\section{Acknowledgements}

The authors would like to thank Ferico S.A for providing the semolina and for financial support.

\section{References}

Aguerre, R.J., Suarez, C., Viollaz, P.E., 1986. Enthalpy-entropy compensation in sorption phenomena: application to the prediction of the effect of temperature on food isotherms. Journal of Food Science 51 (6), 1547-1549.

Baumann, H., 1966. Apparatur nach Baumann zur Bestimmung des Flüssigkeitsaunahme von pulvrigen Substanzen. Fette Seifen Anstrimchmittel 68 (9), 741-743.

Becker, H.A., 1959. A study of diffusion in solids of arbitrary shape with application to the drying of the wheat kernel. Journal of Applied Polymer Science 1, 212226
Bell, L.N., Labuza, T.P., 2000. Moisture Sorption-Practical Aspects of Isotherm Measurement and Use, second ed. AACC Egan Press, Egan, MN.

Buckton, G., 1992. The estimation and application of surface energy data for powdered systems. Drug Development and Industrial Pharmacy 18, 1149-1167.

Chung, D.S., Pfost, H.B., 1967. Adsorption and desorption of water vapor by cereal grains and their products - part I: heat and free energy changes of adsorption and desorption. Transactions of the ASAE 10, 549-551.

Crank, J., 1976. The Mathematics of Diffusion, second ed. Oxford University Press, Oxford, UK.

Dural, N.H., Hines, A.L., 1993. Adsorption of water on cereal bread type dietary fibers. Journal of Food Engineering 20, 17-43.

Everett, D.H., 1950. The thermodynamics of adsorption. Part II. Thermodynamics of monolayers on solids. Transactions of the Faraday Society 46, 942-957.

Favre, E., Nguyen, Q.T., Clément, R., Néel, J., 1996. The engaged species induced clustering (ENSIC) model: a unified mechanistic approach of sorption phenomena in polymers. Journal of Membrane Science 117, 227-236.

Gabas, A.L., Menegalli, F.C., Telis-Romero, J., 2000. Water sorption enthalpy entropy compensation based on isotherms of plum skin and pulp. Journal of Food Science 65 (4), 680-684.

Gutierrez, M.C., Rubio, J., 1999. Inverse gas chromatography: a new approach to the estimation of specific interactions. Journal of Chromatography A 845, 53-66.

Hébrard, A., Oulahna, D., Samson, M.F., Galet, L., Morel, M.H., Abecassis, J., Fages, J., 2001. Étude morpho-granulométrique et structurale des semoules de blé dur en relation avec leurs propriétés d'hydratation et d'agglomération en couscous. Récents Progrès en Génie des Procédés 77, 489-496.

Hébrard, A., Oulahna, D., Galet, L., Cuq, B., Abecassis, J., Fages, J., 2003. Hydration properties of durum wheat semolina: influence of particle size and temperature. Powder Technology 130, 211-218.

Kang, S., Delwiche, S.R., 1999. Moisture diffusion modelling of weat kernels during soaking. Transactions of the ASAE 42, 1359-1365.

Koumoutsakos, A., Avramidis, S., 1999. Enthalpy-entropy compensation in water sorption by various wood species. Holz Als Roh-Und Werkstoff 57, 379-382.

Kratzer, A., 2007. Hydration, dough formation and structure development in durum wheat pasta processing, $\mathrm{PhD}$ dissertation. Swiss federal Institute of Technology Zurich, Switzerland.

Lagoudaki, M., Demertzis, P.G., Kontominas, M.G., 1993. Moisture adsorption behaviour of pasta products. Lebensmittel-Wissenschaft Technologie 26, 512516.

Leffler, J.E., Grunwald, E., 1963. Rates and equilibria of organic reactions. Wiley and sons, New York.

Levoguer, C.L., Booth, J., 1997. Calculation of diffusion constants in thin polymer films using DVS, Dynamic Vapour Sorption. Surface Measurement Systems, Application note 16.

Levoguer, C.L., 1997. Measurement of the surface energies of pharmaceutical powders using a novel vapour adsorption method. Surface Measurement Systems, Application note 17

Madamba, P.S., Driscoll, R.H., Buckle, K.A., 1996. Enthalpy-entropy compensation models for sorption and browning of garlic. Journal of Food Engineering 27, 109-119.

McMinn, W.A.M., Magee, T.R.A., 2003. Thermodynamic properties of moisture sorption of potato. Journal of Food Engineering 60, 157-165.

Resio, C.A., Aguerre, R.J., 1999. Analysis of the sorptional characteristics of amaranth starch. Journal of Food Engineering 42, 51-57.

Roman-Guttierrez A.D., 2002. Propriétés d'hydratation des farines de blé: approches dynamiques et à l'équilibre. PhD dissertation. Science des Aliments, Ecole Nationale Supérieure d'Agronomie de Montpellier, France.

Sun, D.W., Woods, J.L., 1993. The moisture content/relative humidity equilibrium relationship of wheat - a review. Drying Technology 11, 1523-1551.

Tolaba, M.P., Suarez, C., Viollaz, P., 1997. Heats and entropies of cereal grains: a comparison between integral and differential quantities. Drying Technology 15, $137-150$. 